\title{
COVID-19 ve Anne Sütü ile Beslenme
}

\section{COVID-19 Pandemic and Breastfeeding}

\author{
Nalan Karabayır ${ }^{1}$ (D), Serap Sapmaz² (1), Gülbin Gökçay ${ }^{3,4}$ (D)
}

${ }^{1}$ Istanbul Medipol Üniversitesi, Uluslararası Tıp Fakültesi, Sosyal Pediatri Bilim Dalı, İstanbul, Türkiye

${ }^{2}$ İstanbul Üniversitesi, Sağlık Bilimleri Enstitüsü ve Çocuk Sağlığı Enstitüsü, Sosyal Pediatri Doktora Programı, İstanbul, Türkiye

${ }^{3}$ istanbul Üniversitesi, Çocuk Sağıı̆ı̆ Enstitüsü, Sosyal Pediatri Anabilim Dalı, İstanbul, Türkiye

${ }^{4}$ Istanbul Üniversitesi, İstanbul Tıp Fakültesi, Çocuk Sağlığı ve Hastalıkları Anabilim Dalı, Sosyal Pediatri Bilim Dalı, İstanbul, Türkiye

ORCID ID: N.K.0000-0002-8003-1952; S.S. 0000-0001-9677-6986; G.G. 0000-0003-1042-0407

Attf/Citation: Karabayir N, Sapmaz S, Gokcay G. COVID- 19 ve Anne Sütü ile Beslenme. Çocuk Dergisi - Journal of Child 2020;20(2):72-75. https://doi.org/10.26650/jchild.2020.2.772138

öz

Aralık 2019'da Çin'den başlayarak tüm dünyaya yayılan COVID-19 enfeksiyonu doğumdan itibaren yaşamın her evresini etkileyen bir enfeksiyondur. Küçük çocukların çoğunda asemptomatik ya da hafif şiddette seyrettiği bildirilen COVID-19 enfeksiyonuna yakalanan gebe ve çocuk sayısı giderek artmaktadır. Olağanüstü koşullarda sağlığın korunması ve sürdürülmesinde anne sütü ile beslenme çok önemlidir. Anne sütünün hem anne hem de bebek için kısa ve uzun vadede pek çok olumlu etkisi olduğu bilinmektedir. Yenidoğan gereksinimlerine göre düzenlenebilen eşsiz besleyici özelliği yanı sıra anne sütü içinde bulunan biyoaktif maddeler, büyüme ve gelişmeyi etkileyen hormon ve büyüme faktörleri, immün sistemi düzenleyen faktörler ve antienflamatuvar maddeler bebeği enfeksiyonlardan korumaktadır. Ayrıca maternal enfeksiyonda 7 gün içinde anne sütünde saptanan antikorlar da bebekte enfeksiyon riskini azaltmaktadır. Bu sayede anne sütü ile beslenen bebeklerde otitis media, alt solunum yolu enfeksiyonları, gastroenterit ve prematüre bebeklerde nekrotizan enterokolit nadir görülmektedir. Bu zamana kadar yapılan çalışmalarda anne sütünden bebeğe COVID-19 enfeksiyonu bulaştığı bildirilmemiştir. DSÖ anne sütünün yararlarını, formül sütle beslenmenin zararlarını da hesaba katarak COVID-19 enfekte annelerin maske ve el hijyenine dikkat ederek ten temasını ve anne sütüyle beslenmeyi önermektedir. Sağlık personelleri bu önerilerin rehberliğinde emzirmeyi başlatma ve sürdürme konusunda anne-bebek çiftine destek olmalıdır.

Anahtar Kelimeler: COVID 19, anne sütü, emzirme, Dünya Sağlık Örgütü

\section{ABSTRACT}

COVID-19, which spread around the world starting from China in December 2019 , is an infection that affects every stage of life from birth. The number of pregnant women and children infected with COVID-19, which is reported to be asymptomatic or to show mild symptoms in most young children, is increasing. Breastfeeding is paramount in terms of sustaining good health during these exceptional conditions. Breast milk is known to have many positive effects for both the mother and the baby in the short and long term. Breast milk has unique nutritious properties that can be regulated according to neonatal requirements, bioactive substances in breast milk, hormone, and growth factors that affect growth and development factors that regulate the immune system and anti-inflammatory substances which protect the baby from various infections. In addition, antibodies detected in breast milk within 7 days of maternal infection reduce the risk of infection in the baby. In this way, otitis media, lower respiratory tract infections, gastroenteritis, and necrotizing enterocolitis are rare in infants who are breastfed. It has not been reported that COVID-19 infection can be transmitted through breast milk from the mother to the baby. Taking into account the benefits of breast milk and skin to skin contact in contrast with the harms of feeding with formula milk, the WHO advices mothers with COVID-19 to use masks and to pay close attention to hand hygiene. Health care personnels should support the mother in starting and maintaining breastfeeding under the guidance of these recommendations.

Keywords: COVID 19, breast milk, breastfeeding, World Health Organization
Yeni koronavirus hastalığı (COVID-19) doğumdan itibaren başlayarak yaşamın tüm evrelerini etkilemektedir. Çocuklarda COVID 19 yetişkinlere göre daha nadir görülmekte olup, çoğu kez asemptomatik ya da hafif semptomlarla seyretmektedir (1). Özellikle salgın hastalık dönemlerinde emzirmenin koruyucu etkilerinden yararlanmak önem kazanmaktadır. Emzirme yenidoğan, bebek ve çocuk mortalitesini azaltmaktadır. Tüm ekonomik ve coğrafi koşullarda yaşam boyunca sağlık ve çocuk gelişimini iyileştirdiğini gösteren kaliteli kanıtlar mevcuttur.

Anne sütünün, anne bebek çifti, toplum ve çevre sağlığı açısından faydalı etkileri bilinmektedir. Anne sütü yenidoğan bebeğin ihtiyacına uygun olarak düzenlenebilen eşsiz besleyici özelliklerinin yanında bebeği enfeksiyon hastalıklarından koruyan 
biyoaktif maddeler, büyüme ve gelişimi etkileyen büyüme faktörleri ve hormonlar, immünoregülatör ve antienflamatuvar maddeler içerir. Anne sütünün içerdiği salgısal immunglobulin A başta olmak üzere antikorlar, canlı hücreler ve bifidus faktör, laktoferrin, lizozim, glikan ve oligosakkaridler, nükleotidler gibi pek çok anti-enfektif faktörler ile enfeksiyonlara karşı bebeğin korunmasını sağlar (2). Anne sütü ile beslenen bebeklerde bu nedenle otitis media, alt solunum yolu enfeksiyonları, gastroenterit ve prematüre bebeklerde nekrotizan enterokolit nadir görülür. Ayrıca maternal enfeksiyonda 7 gün içinde anne sütünde saptanan antikorlar sayesinde bebekte enfeksiyon riski azalır. Nitekim, Karabayır ve ark. tarafından varisella geçirmekte olan annenin sütünde varisella DNA saptanmasına rağmen bebekte suçiçeği gelişmediği bildirilmiştir (3). Ayrıca H1N1 enfeksiyonunda temas izolasyonuna dikkat edilerek bebeğin anne ile birlikte kalması ve emzirmesinin anne sütünün immunoprotektif etkisi ile bebeği koruyacağı ileri sürülmüştür (4). Bebeğin doğumdan sonra annesinden ayrılması bebeği enfeksiyonlara karşı daha korunmasız duruma getirebilir (5). Emzirilen bebeklerin genellikle hastalandıklarında ağır solunum semptomlarının ortaya çıkma olasılığının daha düşük olduğu bilinmektedir. Anne sütü almayan bebeklerin, en az 4 ay sadece anne sütü alan bebeklere göre pnömoni nedeniyle hastaneye yatma riskinde 3,6 kat artış olduğu bildirilmiştir (6).

Ten tene temasın emzirme başarısının sağlanmasında kritik etkisi olduğu saptanmıştır (7). Anne ve bebeğin ayrılmasının toplam emzirme süresini kısaltması dışında, erken izolasyonun sonuçları olumlu etkilediğine dair kanıtlar da bulunmamaktadır (8). Emzirme, oksitosin hormonunu arttırarak anneyi postpartum depresyondan korumaktadır (9). İzolasyonun hem anne hem de bebek üzerinde yaratacağı stres SARS COV-2 ile enfekte olan anne ve bebeğin hastalık seyrini kötüleştirebileceği akılda tutulmalıdır (8). Anne sütünün yararları sebebi ile Dünya Sağlık Örgütü (DSÖ) salgın hastalıklar gibi olağanüstü koşullar esnasında anne sütü ile beslenmenin sürdürülmesini desteklemektedir (10).

SARS COV-2, öksürme veya hapşırma sırasında saçılan solunum yolu damlacıkları ile bulaşmaktadır. Ayrıca virüsün yüzeylerde birkaç güne kadar hayatta kaldığı gösterilmiştir.

Bu zamana kadar COVID-19'un vertikal geçişi ile ilgili olarak yapılan çalışmalarda amniyon mayi, kordon kanı, süt veya yenidoğan farenks sürüntüsü örneklerinde virüs bulunmamıştır $(11,12)$. Bir çalışmada 26 hasta annenin sütünde nükleik asit negatif bulunurken, bir diğer çalışmada yalnız bir annenin sütünde nükleik asit testi pozitif saptanmıştır. İki gün sonra yapılan testin negatif bulunması ile ilk sonuç yalancı pozitiflik olarak değerlendirilebilir $(13,14)$. De Rose ve ark. tarafından 32 anne bebek çiftinin değerlendirildiği çalışmada da anne sütünde antijen pozitifliği bildirilmemiştir (15). Sonuç olarak virüsün anne sütü ile bulaştığı bilimsel olarak kanıtlanmamıştır.

Enfeksiyonlar sırasında anne sütü ile beslenme rehberleri, influenza, ciddi akut solunum yolu sendromu koronavirusu (Severe Acute Respiratory Syndrome Coronavirus, SARS-CoV) ve Ortadoğu respiratuvar sendrom koronavirusu (Middle East
Respiratory Syndrome Coronavirus, MERS-CoV) gibi diğer viral solunum patojenlerinin bulaşımı ve SARS-CoV-2 hakkında günümüze kadar elde edilen bilgilere dayanmaktadır $(16,17)$. ÇaIışmalarda SARS-CoV ve MERS enfeksiyonlarında vertikal geçiş gösterilmemiş, aksine SARS-CoV enfeksiyonu geçirmekte olan bir annenin sütünde SARS-CoV antikorları saptanmıştır (18).

DSÖ’nün 2016 yılında bebek besleme ve HIV ile ilgili kılavuzu, HIV pozitif annelerin daha önce 1 yıla kadar önerilen anne sütü alma süresinin artık en az 2 yıla kadar devam edilebileceğini bildirilmektedir (19). DSÖ anne/bebek teması ve emzirme ile ilgili önerilerinde yalnızca COVID-19 enfeksiyonunun bebeğe olan riskleri değil, aynı zamanda bebeklerin emzirilmemesi ya da formül sütlerinin uygunsuz kullanımıyla ilişkili ciddi morbidite ve mortaliteler ile ten-tene temas ve anne sütünün protektif etkilerini de göz önünde bulundurmaktadır.

COVID-19 enfeksiyonunda anne ve yenidoğanın ayrılması kararı; anne ve bebeğin klinik durumu, anne (doğrulanmış veya şüpheli) ve bebeğin (bebeğin pozitif test sonucu ayrılma ihtiyacını ortadan kaldırır) SARS-CoV-2 test sonuçları, emzirme isteği, hastanenin yer durumu, taburcu olduktan sonra uygun izolasyon koşullarının varlığı ile izolasyonun riskleri ve yararlarının değerlendirilmesi gibi faktörler dikkate alınarak sağılı çalışanları rehberliğinde anne tarafından verilmelidir. Ten tene temas ve emzirmenin bebeğe olan sayısız faydası, çoğu kez çocuklarda asemptomatik ya da hafif semptomlarla geçen COVID-19 enfeksiyonu riskinden daha fazla olduğundan DSÖ, anne ve bebeğin aynı odada kalmasını ve ten temasını desteklemekte, annenin tıbbi maske ve el hijyenine dikkat ederek emzirmeye devam etmesini önermektedir (20). DSÖ'nün COVID-19'dan etkilenen emziren anneler için önerileri aşağıda belirtilmiştir:

Anne SARS-CoV-2 pozitif ya da şüpheli ise bebeğine dokunmadan önce ellerini 20 saniye boyunca su ve sabunla yıkamalı veya alkollü el dezenfektanı kullanmalıdır. Anne bebeğini emzirirken tıbbi maske kullanmalıdır. Maske nemlendiğinde değiştirilerek kullanılmış maskeler hemen atılmalıdır. Maskeler tek sefer kullanılmalı, ön tarafına dokunulmamalı ve arkadan çözülmelidir. Hapşırma ve öksürme için mendil bulundurmalı, mendil kullandıktan sonra hemen atılmalıdır. Sonrasında sabun ve su ile eller 20 saniye boyunca yıkanmalı veya alkollü el dezenfektanı kullanılmalıdır. Temas edilen yüzeyler düzenli olarak temizlenmelidir. Anne maskesi olmasa dahi emzirmeye devam edebilir. Tıbbi olmayan maskelerin (örneğin ev yapımı veya bez maskeler) kullanımı ile ilgili an itibariyle lehte ya da alehte öneri yapmak mümkün değildir.

Annenin bebeğini emzirmesi olası değil ise anne sütü sağılarak bebeğe verilmelidir. Anne sütünün nasıl sağılacağı annenin tercihine, hijyen koşullarına, ulaşılabilirlik ve maliyete bağııdır. Süt sağma için cihaz elzem değildir, anneye mutlaka elle süt sağımı gösterilmelidir. Pompa kullanımı gerekliyse mutlaka kişiye özel olmalıdır. Anne ve anneye destek olan diğer kişiler, sağımdan ve pompa ya da biberona dokunmadan önce ellerini yıkayarak her kullanımdan sonra ürünleri temizlemelidir. Sağma öncesi meme temizliği, biberon ya da süt saklama poşetlerinin dış yüzlerinin dezenfekte edilmesini destekleyen kanıt yoktur. Eğer kesin/olası 


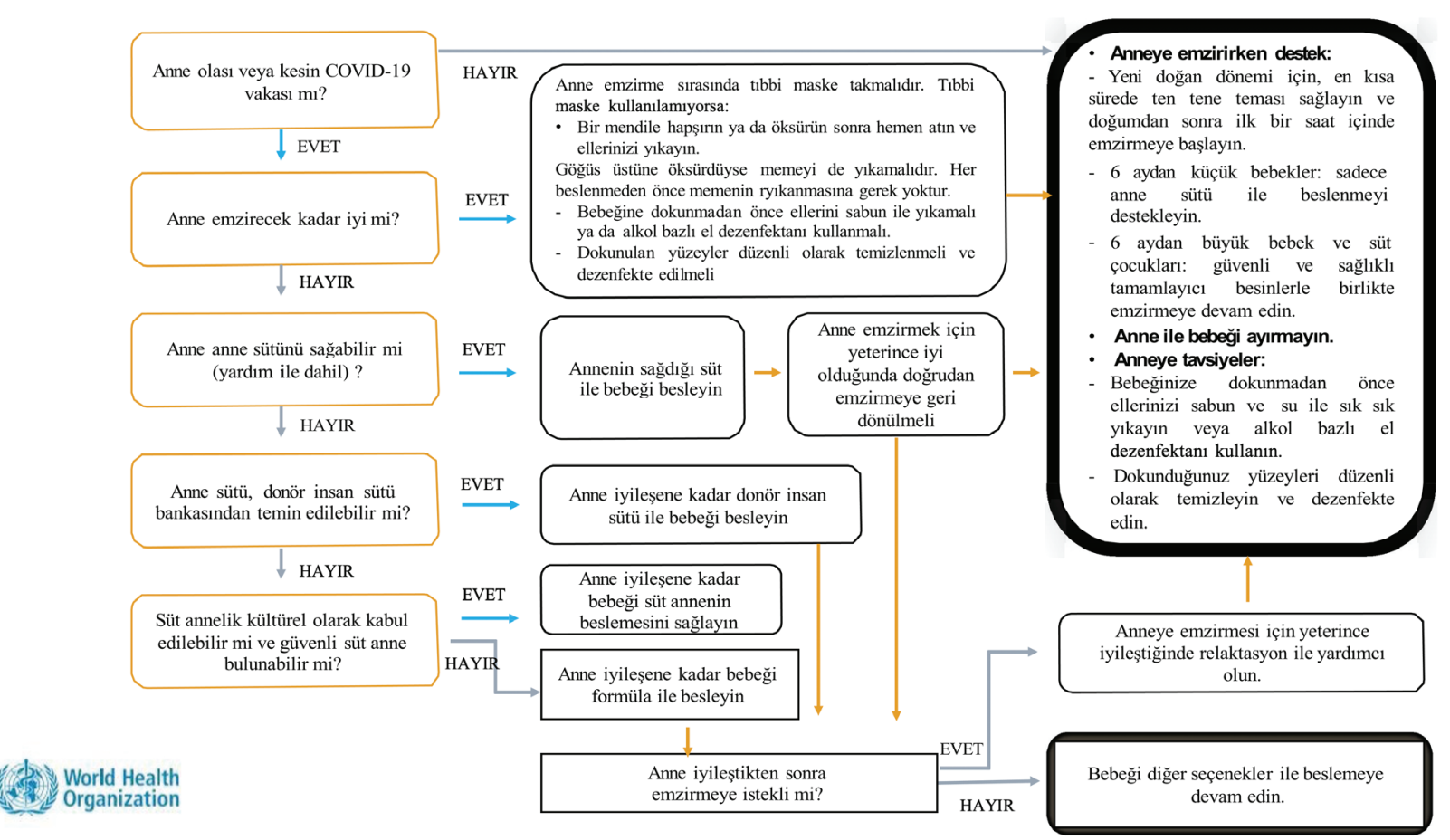

Şekil 1: COVID-19 ve anne sütü ile beslenme.

COVID-19 tanılı anne memesi üzerine öksürürse beslenme öncesinde en az 20 saniye nazikçe ılık su ve sabun ile memesini yıkaması gerekir. Her emzirme öncesinde veya süt sağmadan önce rutin olarak meme temizliği yapılması gereksizdir. Sağılmış sütanne ya da hastalık belirtisi olmayan başka bir yetişkin tarafından ve tercihen temiz bir kaşık (daha basit) ve/veya fincan kullanılarak, el yıkandıktan sonra bebeğe verilmelidir. DSÖ, sağıImış anne sütünün olmadığı durumlarda süt bankasından anne sütü temini ya da kültürel olarak kabul görüyor ve güvenilir bir anne bulunabiliyorsa, sütanneliği önermektedir. Kesin/ olası COVID-19 tanılı bir anne, tanıdan sonra belirli bir süre beklemeksizin kendini yeterince iyi hissettiğinde emzirmeye başlayabilir. Emzirmenin, annedeki COVID-19 enfeksiyonunun seyrini etkilediğine dair kanıt bulunmamaktadır. Annenin tam olarak iyileşebilmesi için genel sağlığı ve beslenmesi desteklenmelidir (Şekil 1).

Sonuç olarak, COVID-19 enfeksiyonu esnasında anne-bebek teması ve emzirmeye ilişkin kararlar, sağlık çalışanları ile birlikte anne ve ailesi tarafından alınmalıdır. Sağlık personelleri anneyi anne sütü konusunda desteklemeli ve teşvik etmelidir. Emzirme ve ten tene temas hastane kalış zamanını ve pandemi döneminde karantina ve stresle bağlantılı negatif etkileri azaltacaktır.

\section{Hakem Değerlendirmesi: Dış bağımsız.}

Yazar Katkıları: Çalışma Konsepti/Tasarım- N.K., S.S., G.G.; Veri Toplama- N.K., S.S., G.G.; Veri Analizi/Yorumlama- N.K., S.S.,G.G.; Yazı Taslağı- N.K., S.S.,G.G.; İçeriğin Eleştirel İncelemesi- N.K., S.S.,G.G.; Son Onay ve Sorumluluk- N.K., S.S.,G.G.; Süpervizyon- N.K., G.G.

Çıkar Çatışması: Yazarlar çıkar çatışması beyan etmemişlerdir.
Finansal Destek: Yazarlar finansal destek beyan etmemişlerdir.

Peer Review: Externally peer-reviewed.

Author Contributions: Conception/Design of Study- N.K., S.S., G.G; Data Acquisition- N.K., S.S., G.G.; Data Analysis/Interpretation- N.K., S.S.,G.G.; Drafting Manuscript- N.K., S.S.,G.G.; Critical Revision of Manuscript- N.K., S.S.,G.G.; Final Approval and Accountability- N.K., S.S.,G.G.; Supervision- N.K., G.G.

Conflict of Interest: Authors declared no conflict of interest.

Financial Disclosure: Authors declared no financial support.

\section{KAYNAKLAR/REFERENCES}

1. Castagnoli R, Votto M, Licari A, Brambilla I, Bruno R, Perlini S, et al. Severe Acute Respiratory Syndrome Coronavirus 2 (SARS-CoV-2) Infection in Children and Adolescents: A Systematic Review. JAMA Pediatr 2020 Apr 22. doi: 10.1001/jamapediatrics.2020.1467 Epub ahead of print. PMID: 32320004.

2. Gokcay G, Keskindermirci G. Breastmilk and Covid-19. J Ist Faculty Med Published online March 23, 2020. doi: 10.26650/ IUITFD.2020.0025

3. Karabayir N, Yaşa B, Gökçay G. Chickenpox infection during lactation. Breastfeed Med 2015;10(1):71-2.

4. Sendelbach DM, Sanchez PJ. Varicella, influenza: not necessary to separate mother and infant. Pediatrics 2012 Aug;130(2):e464; author reply 465-6.

5. Halperin BA, Morris A, Mackinnon-Cameron D, J Mutch, J M Langley, $S$ A McNeil, et al. Kinetics of the antibody response to tetanusdiphtheriaacellular pertussis vaccine in women of childbearing age and postpartum women. Clin Infect Dis 2011;53:885-92. 
6. Bachrach VR, Schwarz E, Bachrach LR. Breastfeeding and the risk of hospitalization for respiratory disease in infancy: a meta-analysis. Arch Pediatr Adolesc Med 2003;157:237-43.

7. Lau Y, Tha PH, Ho-Lim SST, Wong LY, Lim PI, Citra Nurfarah BZM, et al. Analysis of the effects of intrapartum factors, neonatal characteristics, and skin-to-skin contact on early breastfeeding initiation. Matern Child Nutr 2018;14(1). doi: 10.1111/mcn.12492

8. Stuebe A. Breastfeed Med 2020; Apr 7. doi: 10.1089/bfm. 2020. 29153.ams

9. Dias CC, Figueiredo B. Breastfeeding and depression: a systematic review of the literature. J Affect Disord 2015 Jan;171:142-54.

10. World Health Organization, Guiding principles for feding infants and young children during emergencies. 2004, Geneva WHO/ $\mathrm{NHD} / 99.10$

11. Della Gatta AN, Rizzo R, Pilu G, Simonazzi G. Coronavirus disease 2019 during pregnancy: a systematic review of reported cases. Am J Obstet Gynecol 2020 Jul;223(1):36-41. doi: 10.1016/j. ajog.2020.04.013. Epub 2020 Apr 18. PMID: 32311350; PMCID: PMC7165087.

12. Qiancheng X, Jian S, Lingling P, Lei H, Xiaogan J, Weihua L, et al. Sixth batch of Anhui medical team aiding Wuhan for COVID-19. Coronavirus disease 2019 in pregnancy. Int J Infect Dis 2020 Jun;95:376-83. doi: 10.1016/j.ijid.2020.04.065. Epub 2020 Apr 27. PMID: 32353549; PMCID: PMC7185021.

13. Elshafeey F, Magdi R, Hindi N, Elshebiny M, Farrag N, Mahdy S, et al. A systematic scoping review of COVID-19 during pregnancy and childbirth. Int J Gynaecol Obstet 2020 Jul;150(1):47-52. doi: 10.1002/ijgo.13182. Epub 2020 May 17. PMID: 32330287.

14. Wu Y, Liu C, Dong L, Zhang C, Chen Y, Liu J, et al. Coronavirus disease 2019 among pregnant Chinese women: Case series data on the safety of vaginal birth and breastfeeding. BJOG 2020 May 5;127(9):1109-15. doi: 10.1111/1471-0528.16276. Epub ahead of print. PMID: 32369656; PMCID: PMC7383704.
15. De Rose DU, Piersigilli F, Ronchetti MP, Santisi A, Bersani I, Dotta et al. Study Group of Neonatal Infectious Diseases of The Italian Society of Neonatology (SIN). Novel Coronavirus disease (COVID-19) in newborns and infants: what we know so far. Ital J Pediatr 2020 Apr 29;46(1):56. doi: 10.1186/s13052-020-0820-x. PMID: 32349772; PMCID: PMC7190200.

16. Royal College of Paediatrics and Child Health. COVID-19-guidance for paediatric services. RCPCH. London. Erişim: https://www.rcpch. ac.uk/sites/default/files/generated-pdf/ document/COVID-19--guidance-for-paediatric-services.pdf. Erişim Mayıs 2020, https:// abm.memberclicks.net/abm-statement-coronavirus erişim Mayıs 2020.

17. Schwartz DA, Graham AL. Potential Maternal and Infant Outcomes from (Wuhan) Coronavirus 2019-nCoV Infecting Pregnant Women: Lessons from SARS, MERS, and Other Human Coronavirus Infections. Viruses 2020 Feb 10;12(2). pii: E194.

18. Robertson CA, Lowther S, Birch T, Tan C, Sorhage F, Stockman L, et al. SARS and Pregnancy: A Case Report. Emerg Infec Dis 2004;Feb;10(2):345-8. doi: 10.3201/eid1002.030736. PMID: 15030710; PMCID: PMC3322896.

19. Unicef. Nutrition. Advocacy Brief. Breastfeeding and HIV. Global breastfeeding collective. Erişim: https://www.unicef.org/ nutrition/files/Global_Breastfeeding_Collective_Advocacy_Brief_ Breastfeeding_and_HIV.pdf Son erişim tarihi: 30 Nisan 2020

20. Dünya Sağlık Örgütü. https://www.who.int/docs/defaultsource/maternal- health/faqs-breastfeeding-and-covid-19. pdf?sfursn=d839e6c0_1 Erişim : 30 Nisan 2020 